
Brasil e Moçambique). PROCESSO 491342/2005-5 - Ed. 472005 Cham. 1/Chamada. APOIO FINANCEIRO: CNPq e UNESCO

\title{
Educar para outro mundo possível diante dos desafios colocados pela globalização capitalista
}

\author{
Elifas Levi da Silva \\ Elisabete Ferreira Esteves Campos \\ Lucimara Rocha de Oliveira \\ Manuel Marquez Viscaíno Júnior
}

\begin{abstract}
RESUMO
A palavra globalização, de tão repetida, acabou esvaziada de significado. Tentando explicar tudo, acaba não explicando nada. Nesse vazio de sentido nos apoiamos em três grandes pensadores de nosso tempo, István Mészáros, Zygmunt Bauman e António Teodoro, acerca do que é a globalização, seus conceitos, suas raízes, seus efeitos, com especial atenção ao papel da educação e da escola neste cenário. Cada um dos autores contribui com o debate abordando certos aspectos dos processos de globalização em nossa sociedade capitalista, apontando os problemas decorrentes do predomínio das leis de mercado. Pode-se dizer que a globalização iniciou-se com as grandes navegações, mas os processos de globalização capitalista se intensificaram em razão da crise petrolífera dos anos 70. Com o desenvolvimento tecnológico, a Internet, sociedades transnacionais e outros fatores, o mercado passou a alcançar o mundo e não mais um ou outro determinado país, retirando o poder das nações, submetendo os países e seus povos aos interesses do capital. Apesar disso, há autores que acreditam na possibilidade da construção de alternativas a essa forma de globalização capitalista, por meio da ruptura com o ordenamento do sistema do capital. E nesta tarefa, a educação, de uma forma mais ampla, teria como objetivo o enfrentamento das internalizações hegemônicas, com vistas a uma nova conscientização que supere a reificação do capital. A educação, nesse sentido, pode construir uma outra lógica, através da formação da consciência crítica, contra a educação consumista, contra a degradação ambiental, as desigualdades, as guerras, valorizando e assumindo os direitos humanos, a diversidade cultural, a participação de todos na vida social e nos processos decisórios.
\end{abstract}

Palavras-chave: capitalismo, educação, globalização.

\section{Título em inglês: EDUCATION FOR ANOTHER POSSIBLE WORLD IN ORDER TO MAKE HEAD AGAINST THE CHALLENGES OF CAPITALIST GLOBALIZATION}

\begin{abstract}
The word globalization, openly used, it is becoming meaningless. It has been used for trying to explain everything but, in fact, it does not explain anything. To reflect about this meaningless we look for theoretical supporting in ideas of three great contemporaneous thinkers: István Mészáros, Zygmunt Bauman and António Teodoro, concerning to what is globalization, its concepts, its roots, its effects, with special attention to the role of education and of the school among this scenario.
\end{abstract}


Each author contributes to the discussion broaching some aspects about globalization processes in our capitalist society and indicating decurrent problems of the predominance of market laws. We can say that globalization began during the period of great navigations, but the globalization processes intensified in the petroliferous crises at 70 's. From the technological development, the Internet, transnational societies and others factors, the market started to attain the whole world instead of a certain country. It takes the power of the nations and it submits the countries and their people to the capital interests. Although, there are authors who believe in the possibility of construction of alternatives to capitalism, through the rupture in the ordainments of the system of capital. In this task, the education, in a large way, would have the aim of to face the hegemonic internalizations for a new conscience able to win the reification of the capital. Education, in this way, can construct another logic through the formation of a critical conscience against the consumist education, against the environment degradation, inequalities, wars. Instead of it all, education can valorize and assume the human rights, the cultural diversity, the participation of everybody in the social life and in the decidable processes.

Index Terms: capitalism, education, globalization.

\section{Introdução}

Este texto pretende abordar a temática da educação para outro mundo possível ${ }^{1}$, em função das implicações decorrentes dos processos de globalização capitalista que vêm contribuindo para o aumento das desigualdades e degradação do planeta, intensificando as guerras e a violência. A construção de um outro mundo nos desafia a lutar por melhores condições de vida para todos em termos de acesso à educação, à saúde, à habitação, ao lazer e alimentação. É preciso construir um mundo mais humano.

Alcançar tal propósito, no entanto, é extremamente complexo. As relações sociais, econômicas, políticas, pautadas na lógica capitalista, determinam certa forma de organização da sociedade, onde as desigualdades se naturalizam. Nesse contexto, muitos não têm consciência do quanto são opressores e oprimidos ${ }^{2}$ nas relações que estabelecem, ou podem acreditar que são relações naturais, inerentes à condição de nossa existência. Mudar essa sociedade, a qual engendra esse tipo de atitude, é nosso desejo, mas ainda não sabemos como fazê-lo. Não sabemos como construir "outro mundo" ou "outros mundos", onde a diversidade de toda ordem seja respeitada, outras formas de relações se constituam de maneira mais justa, onde as leis de mercado não se sobreponham aos direitos humanos.

\footnotetext{
${ }^{1}$ Esse tema foi discutido na disciplina Perspectivas atuais da educação, ministrada pelo Professor Moacir Gadotti, do Programa de Pós Graduação da Faculdade de Educação da Universidade de São Paulo, no primeiro semestre de 2006.

${ }^{2} \mathrm{O}$ conceito de opressor e oprimido foi elaborado por Paulo Freire. A esse respeito ver FREIRE, Paulo. Pedagogia do Oprimido, Rio de Janeiro: Paz e Terra, 1987. Esse conceito é sempre retomado em outras obras do autor.
} 
O propósito deste texto é apresentar algumas reflexões que possam contribuir com esse debate. E que alimentem uma prática transformadora.

\section{Um mundo que precisa ser modificado}

Paulo Freire, cujas proposições teóricas embasaram a pesquisa de Ângela Antunes $(2002)^{3}$, ensina que precisamos ler o mundo. É necessário conhecermos a realidade para transformá-la, o que implica compreender a razão das desigualdades, da violência, das injustiças e de tantas outras mazelas que atingem milhões de seres humanos.

Milton Santos (apud ANTUNES, 2002, p. 3) acredita que há um discurso hegemônico que tenta nos convencer de que o mundo vem tornando-se uma grande comunidade, uma aldeia global que tem à sua disposição os recursos necessários para um crescimento econômico ilimitado, podendo proporcionar vida melhor a toda a humanidade. Hoje temos a difusão instantânea de informações, processos produtivos ágeis, flexíveis e altamente rentáveis. Mas rentáveis para quem?

No dizer de Bauman (1999), as mudanças que acompanharam o aumento na velocidade das comunicações e dos transportes, ao mesmo tempo em que os Estados nacionais eram abalados em seus fundamentos pela lógica demolidora da globalização econômica, resultaram numa compressão da relação espaço-tempo e numa extraterritorialidade que alteraram significativamente a condição humana, criando uma nova polarização social difícil de perceber, mas muito mais ainda de superá-la, ou de alterá-la significativamente:

[...] em vez de homogeneizar a condição humana, a anulação tecnológica das distâncias temporais/espaciais tende a polarizá-las. Ela emancipa certos seres humanos das restrições territoriais e torna extraterritoriais certos significados geradores de comunidade - ao mesmo tempo em que desnuda o território, no qual outras pessoas continuam sendo confinadas [...] (BAUMAN, 1999, p. 25).

Tais mudanças, comumente associadas ao fenômeno da globalização, resultaram, de acordo com Bauman (1999), num novo fator de estratificação social, mais poderoso e cobiçado: a "mobilidade". Adquirida por aqueles que "investem", aqueles que possuem capital, essa "mobilidade" inaugura situações sociais que colocam em xeque as possibilidades de que ações coletivas possam interferir sobre os rumos de sua evolução e de seu desenvolvimento. Partindo da categoria conceitual de "proprietário ausente", representado pela nova elite que pode mover-se livremente sem se preocupar com o que

\footnotetext{
${ }^{3}$ Em sua Tese de Doutorado, Antunes (2002) apresenta o conceito de planetarização, defendendo que a escola deve formar o cidadão do planeta.
} 
deixa e com os que ficam para trás, Bauman (1999) aponta para um quadro sombrio e preocupante, no qual as rupturas nas relações sociais se acentuam e mudanças culturais profundas levam a diversas formas de "isolamento": das elites, os globais, que querem sua inusitada liberdade total de movimento e ação preservada; e dos comuns, os locais, imobilizados cada vez mais em seus locais de vida, mas dos quais possuem cada vez menos o controle.

Num contexto de tal magnitude, que apenas esboça o denso pensamento de Zygmunt Bauman (1999), as possibilidades de ruptura são limitadas e imprevisíveis.

István Mészáros (2005) apresenta uma outra abordagem das dificuldades impostas às sociedades e aos indivíduos no atual momento de sua evolução histórica. Revisitando e atualizando o pensamento marxista, Mészáros vê possibilidades reais de ruptura e de superação dessa lógica desumanizadora imposta pelo "sistema do capital". Mas, para isso, é necessário possuir a compreensão da dinâmica e do funcionamento desse sistema, tanto de seus "mecanismos materiais e econômicos de reprodução, quanto de suas construções ideológicas e valorativas, criadoras de consensos e conformidades hegemônicas nas quais a educação formal", segundo o autor, desempenha um papel determinante.

Como Mészáros (2005), entendemos que os problemas da atualidade são bastante preocupantes. Perguntamo-nos, quase que diariamente: Até onde o colapso ambiental que vivenciamos será suportável? Até onde a marginalização e a violência social caminharão lado a lado com a opulência e a vaidade de uma elite mundial, encantada pelas possibilidades aparentemente inesgotáveis de prazer e consumo, oferecidas por um capitalismo globalizado que avança cada vez mais em suas formas de reprodução?

No campo mais imediato e histórico de defesa das condições de trabalho, estamos apreensivos, pois sabemos que a preocupação central das empresas é o aumento do lucro e, para obtê-lo, uma das primeiras medidas é o corte de funcionários. $\mathrm{O}$ achatamento salarial também é comum, e as empresas não se preocupam se a remuneração do trabalhador será suficiente, ou não, para que ele tenha uma vida digna. O que conta são as "leis de mercado". Se o mercado remunera mal, "não há nada a fazer" — é o que dizem. Para István Mészáros (2005), a "mercantilização das relações sociais e dos indivíduos" desumaniza-os, tornando-os meramente objetos de produção e reprodução de uma ordem social alienante e sufocante, pela qual a felicidade de poucos é justificada com o sofrimento e a angústia de muitos. Falar em justiça, em igualdade e em humanismo tornase, assim, um discurso vazio, por isso o autor enfatiza-se a urgência de se instituir uma radical mudança estrutural. No entanto, as mudanças que têm sido realizadas resultaram 
em "reformas", ou seja, pequenos ajustes para corrigir algum detalhe defeituoso da ordem estabelecida, mantendo intactas as determinações estruturais fundamentais da sociedade como um todo, em conformidade com as exigências inalteráveis da lógica global de um determinado sistema de reprodução, regido pela lógica do capital. Há regras gerais, preestabelecidas, que podem ser ajustadas, mas nunca alteradas.

Mészáros (2005) argumenta que "as determinações fundamentais do sistema do capital são irreformáveis"; por isso, sua proposta de transformação aponta para a necessidade de um processo de reestruturação radical, o qual deve ser orientado pela estratégia de uma reforma concreta e abrangente de todo o sistema; se queremos mudanças significativas, "é preciso romper com a lógica do capital". No seu entendimento, não há como emancipar o ser humano e dotá-lo de uma vida plena de significados elevados e libertadores enquanto homens e mulheres estiverem acorrentados à camisa de força do capital. Como exemplo da tendência do desenvolvimento sob a ordenação imposta pelo sistema do capital na sua fase global, Mészáros cita dados da ONU, no Relatório sobre o Desenvolvimento Humano (2004):

[...] o $1 \%$ mais rico do mundo aufere tanta renda quanto os $57 \%$ mais pobres. A proporção, no que se refere aos rendimentos, entre os $20 \%$ mais ricos e os $20 \%$ mais pobres no mundo aumentou de 30 para 1 em 1960, para 60 para 1 em 1990 e para 74 para 1 em 1999, e estima-se que atinja os 100 para 1 em 2015. Em 1999-2000, 2,8 bilhões de pessoas viviam com menos de dois dólares por dia, 840 milhões estavam subnutridos, 2,4 bilhões não tinham acesso a nenhuma forma aprimorada de saneamento, e uma em cada seis crianças em idade de freqüentar a escola primária não estava na escola. Estima-se que cerca de $50 \%$ da força de trabalho não agrícola esteja desempregada ou subempregada. (MÉSZÁROS, 2005, p. 73-74).

São dados impressionantes que revelam a grande concentração de riqueza nas mãos de poucos e a redução de muitos a uma condição de vida precária e desumanizadora. Tomando por base tais dados, fica evidente que o progresso industrial, científico e tecnológico não beneficia a todos. Os bens materiais e culturais não estão igualmente ao alcance de todos. São razões suficientes para Mészáros (2005) defender o rompimento com a lógica capitalista, uma vez que não há como encontrar a felicidade coletiva e uma relação de respeito e equilíbrio com a natureza, enquanto o objetivo último das relações sociais de produção for pautado pela lógica da acumulação e criação de necessidades artificiais de consumo, levando a uma competição desenfreada e irreversível, que aprisiona a humanidade num círculo vicioso de "desperdício e escassez".

Nesse sentido, Antunes (2002) apresenta alguns indicadores, destacados por Boaventura de Sousa Santos, que reforçam essa compreensão de Mészáros (2005) a respeito da urgência de se romper com essa lógica reprodutiva, imposta pelo sistema do 
capital. Dentre tais indicadores, destaca a enorme concentração de poder econômico por parte das empresas multinacionais, enquanto se perpetua uma desigualdade crônica no acesso à riqueza socialmente produzida em escala global. A continuidade dessa tendência nos últimos 10 anos pode ser percebida pelos dados apresentados pelo Relatório do Desenvolvimento do Banco Mundial de 1995: no conjunto formado pelos países pobres, vivia $85,2 \%$ da população mundial, detendo apenas $21,5 \%$ do rendimento mundial, enquanto o conjunto formado pelos países ricos, com 14,8\% da população mundial, detinha 78,5\% do rendimento mundial. Em 1995, uma família africana média consumia 20\% menos do que consumia 25 anos antes, em 1970 (ANTUNES, 2002, p.34).

Para Milton Santos, citado pela autora, esse mundo globalizado está impondo-se como uma fábrica de perversidades. Há desemprego estrutural, aumento da pobreza, concentração cada vez maior da riqueza, individualismo, competitividade, imposição do mesmo padrão cultural em escala planetária - as mesmas músicas, os mesmos filmes, as mesmas roupas, as mesmas comidas, os mesmos valores em diversas partes do mundo além da banalização da violência.

O que podemos perceber com o estudo dos autores citados é que todos eles denunciam as terríveis condições de existência para alguns, e a intensificação de uma acumulação consumista para outros, as quais se acentuaram com o processo de globalização capitalista. O conceito, o entendimento e o significado da globalização para tais pensadores, no entanto, é bastante diversificado, talvez até contraditório, o que possibilita um interessante campo de reflexão, para o qual iremos agora.

\section{0 que é a globalização?}

Boaventura de Sousa Santos (apud TEODORO, 2003, p. 93-94), define globalização como "conjuntos de relações sociais que se traduzem na intensificação das interações transacionais, sejam elas práticas interestatais, práticas capitalistas globais ou práticas sociais e culturais transnacionais".

Muitos autores divergem quanto à época em que os processos de globalização tiveram início. Alguns consideram que as grandes navegações poderiam ser o marco inicial. É possível considerar, no entanto, que os processos de globalização capitalista se intensificaram com a crise petrolífera dos anos 70, com o desenvolvimento tecnológico, a Internet, as sociedades transnacionais e outros fatores. $\mathrm{O}$ mercado passou a alcançar o mundo e não mais um ou outro determinado país. 
Para António Teodoro o desenvolvimento deixou de ser uma questão nacional para ser progressivamente global, dependendo cada vez mais do mercado mundial, sob um gerenciamento global que tem no chamado "consenso de Washington" os seus dez mandamentos. ${ }^{4} \mathrm{O}$ projeto de desenvolvimento global - ou globalização - possui, por um lado, uma estratégia de liberalização e, por outro, a afirmação do axioma das vantagens competitivas. Estados mais competitivos atraem investimentos das corporações transacionais para os seus territórios. Para este autor, a globalização não resulta de uma imposição de um país sobre o outro, mas antes, e muito mais, do efeito de uma construção supranacional. O comércio mundial possui suas regras fixadas pela Organização Mundial do Comércio (OMC). Os órgãos internacionais passam a ter papel preponderante nas relações entre os países. O papel do Estado como nação é redimensionado pela regulamentação internacional.

Conforme sua proposta de análise e problematização, António Teodoro procura vincular o processo da globalização à questão educacional, demonstrando que muitos países - como Brasil e Portugal - ficam submetidos ao controle externo, no que se refere não só às questões econômicas como também a Projetos Educacionais, Avaliações e Políticas de Educação. A retórica da racionalização e eficácia do ensino vem sendo pano de fundo para a definição de políticas públicas educacionais sob a orientação técnica dos órgãos internacionais. Os relatórios, documentos, índices organizados e divulgados por tais órgãos justificam a adoção de políticas impulsionadas por uma crença no valor econômico da educação. Assim, num determinado período nesse processo de desenvolvimento econômico, os investimentos tiveram como objetivos a educação técnica e o ensino científico, depois, a educação de base e geral. No entanto, para o citado autor, a educação está sujeita às influências na semiperiferia das preocupações das agências hegemônicas, passa a constituir um campo de globalização de baixa intensidade - e, portanto, de baixa regulação -, oportunizando ações contra-hegemônicas de emancipação.

As ações contra-hegemônicas surgem a partir do conceito proposto por Boaventura de Sousa Santos, o qual não utiliza o termo globalização, mas processos de globalizações hegemônicas e contra-hegemônicas. Para Sousa Santos, as globalizações hegemônicas ocorrem "de cima para baixo" e as contra-hegemônicas, "de baixo para cima". Nas globalizações hegemônicas, situa-se o globalismo localizado em que as são questões globais se tornam locais como a poluição, o lixo e outras. Neste localismo globalizado, os

\footnotetext{
${ }^{4}$ Conforme A. Teodoro (2003, p.84)., os dez mandamentos do chamado "consenso de Washington" são: disciplina fiscal, prioridades na despesa pública, reforma fiscal, liberalização financeira, taxas de câmbio, liberalização do comércio, investimento estrangeiro direto, privatização, desregulação e direitos de propriedade.
} 
processos locais se transformam em globais, como a língua inglesa, a música norteamericana, os fast-food. As políticas de Margareth Thatcher e do consenso de Washington, assumidas por agências internacionais como o Banco Mundial, podem ser consideradas como localismo globalizado, a partir da política neoliberal.

As globalizações hegemônicas podem ser de baixa intensidade ou de alta intensidade. Os processos de alta intensidade são rápidos, nos quais o Estado tem pouca participação, como nas Bolsas de Valores. Os processos de baixa intensidade são mais lentos e difusos.

As globalizações contra-hegemônicas compreendem o cosmopolitismo (conjunto de organizações como o Fórum Social Mundial e os diversos movimentos sociais que ganham dimensão e se globalizam, provocando mudanças importantes) e o patrimônio comum da humanidade (desde o espaço, os oceanos, as florestas, os patrimônios intelectuais, culturais e outros). Para Boaventura de Sousa Santos (apud TEODORO, 2003), a alternativa a uma pretensa racionalização das estruturas e das práticas educativas, impostas pela mercadorização do direito à educação e que tem na comparação internacional da avaliação dos resultados escolares o referente legitimador de toda a sua ação, terá seguramente como cerne a transformação do Estado nacional em movimento social, apostado no reforço da democracia redistributiva e participativa.

Zygmunt Bauman (1999) aborda de maneira diferente não só o significado e o alcance da globalização como, também, as possibilidades de superá-la. Para o autor, a mobilidade transformou-se no novo fator que move a luta de classes na era da informação globalizada. De um lado, uma nova elite, difícil de reconhecer segundo os critérios políticos usuais, a elite que pode mover-se, é convidada a fazê-lo, e movimenta o fluxo da riqueza com o seu deslocamento, seja por meio da informação virtual e imediata, ou em seguidas viagens que criam uma familiaridade itinerante. De outro lado, aqueles que ficaram localizados, restringidos em sua liberdade de movimentação, os locais, restrições que se colocam tanto em termos de mobilidade social quanto espacial e de acesso às informações. Longe de demonstrar sinais de fraqueza, essa nova polarização social, para Bauman (1999), caminha para o isolamento mútuo dentro dos quais as pessoas devem se adaptar "para sobreviver às necessidades da nova era do conhecimento tecnológico".

O sociólogo polonês (1999) não considera a globalização um processo único e homogêneo, identificável e concatenado, mas sim um processo obscuro e não-identificável, de forma ambígua e complementar. Partindo da compressão da relação espaço-tempo com a intensificação da velocidade dos movimentos causada pelas modernas tecnologias de 
transporte e comunicações, Bauman (1999) entende a globalização como um movimento mundial de superação das dimensões territoriais, a extraterritorialidade, na qual se cria uma mobilidade tanto de pessoas e informações quanto de capitais e investimentos, que escapa às formas conhecidas e modernas de controle. Segundo o autor, o "significado mais profundo transmitido pela idéia da globalização é o do caráter indeterminado, indisciplinado e de autopropulsão dos assuntos mundiais; a ausência de um centro, de um painel de controle, de uma comissão diretora, de um gabinete administrativo"; a globalização é uma espécie de "desordem mundial” com outro nome.

Nesse cenário mundial da globalização, Bauman (1999) percebe a crise e a superação de processos mundiais que eram desejáveis e procurados durante o auge industrial moderno, e que se entendia - de forma equivocada como é possível perceber hoje - faziam parte de uma idéia de expansão global pensada e controlada. É o caso das idéias e conceitos de "universalização", "civilização", “desenvolvimento", “convergência”, "consenso", e muitos outros termos centrais do pensamento moderno inicial e clássico, que transmitiam "a esperança, a intenção e a determinação de se produzir a ordem", uma ordem que era pensada em escala universal, verdadeiramente global, de tal forma que se tornava uma declaração de intenções, no sentido de se "tornar semelhantes às condições de vida de todos, em toda parte", dando oportunidades de vida para todos, no sentido de torná-las iguais. E ainda, para o citado autor, nada restou desse conjunto de intenções no significado de globalização, tal como a entende no discurso atual, pois o novo termo refere-se, primordialmente, aos efeitos globais não pretendidos e imprevistos, e não "às iniciativas e empreendimentos globais".

Bauman (1999) afirma que a globalização em curso corresponde, sem possibilidade de retorno, à superação do "tripé" de sustentação da soberania legislativa e executiva do Estado moderno, apoiada nas soberanias militar, econômica e cultural. Esse princípio da soberania do Estado de forma global, sustentado pelas soberanias militar, econômica e cultural, teria sido substancialmente abalado e modificado pelo "Grande Cisma" moderno, representado pela formação de dois grandes blocos de poder mundial, liderados pelos Estados Unidos e pela ex-União Soviética. Ao dividirem o mundo, estes blocos criaram mecanismos de integração territorial e política que, na prática, deslocaram, gradualmente, a noção de soberania do Estado, de uma forma isolada e auto-suficiente para mecanismos de integração 'supra-estatal' que redesenharam o "cenário global”, cada vez mais como um "teatro da coexistência e da competição" entre grupos de Estados. A auto-suficiência 
militar, econômica e cultural do Estado, e de qualquer Estado, deixou de ser, então, uma perspectiva viável.

Pressionados pelas mudanças desencadeadas pelo salto radical da tecnologia da velocidade e pela superação da territorialidade com a compressão espaço-temporal, os Estados nacionais se viram obrigados a buscar alianças e a entregarem, cada vez mais, de forma voluntária, parcelas de sua soberania "para preservar sua capacidade de policiar a lei e a ordem”. Para Bauman (1999), quando a polarização supra-estatal do Grande Cisma foi superada, descobriu-se um cenário desconhecido, povoado por estranhas personagens: Estados fragmentados, que desistiam dos seus direitos de soberania; etnias esquecidas ou quase extintas eram reinventadas, almejando um Estado próprio que possibilitasse a inserção no novo cenário global; nações velhas ou novas rompiam com seus pactos federalistas e buscavam a independência para dissolvê-la, depois, nos mecanismos supranacionais, como o Mercado Comum Europeu e a OTAN; e multiplicou-se, de forma imprevista, o número de nações que corriam para instalar-se nos já superlotados escritórios da ONU.

Citando Cornelius Castoriadis, Bauman (1999) demonstra como - na base econômica do tripé de sustentação do Estado - o abalo foi maior e mais rápido, com o abandono da função de manter o equilíbrio dinâmico (igualdade aproximada entre os ritmos de crescimento do consumo e de elevação da produtividade) e a renúncia aos princípios keynesianos de "estimulação estatal da demanda interna". A porosidade das economias nacionais e a condição efêmera e extraterritorial em que operam, faz, então, com que os mercados financeiros globais imponham suas leis, seus preceitos e suas metas ao planeta, como um todo. Nessa perspectiva, a definição de globalização nada mais seria do que a extensão totalitária dessa lógica econômica a todos os demais aspectos da vida, político, cultural e social. Nesta direção, a função de manter a ordem propícia a esse cenário por meio do seu poder de repressão, criando um ambiente de segurança, no qual as mega-empresas globais e a nova classe no topo da hierarquia social tenham garantida sua mobilidade, sua condição de extraterritorialidade global fica sob responsabilidade estatal. A economia, por sua vez, tende a se distanciar cada vez mais da política, criando a idéia da "economia não-política", dando liberdade e flexibilidade à movimentação dos capitais globalizados e não interferindo, sob a ameaça de imediata e furiosa punição por parte dos mercados globais. Nessa perspectiva, a única tarefa econômica ainda permitida aos Estados seria a da garantia de um orçamento equilibrado, policiando e controlando as pressões 
locais por intervenções na direção dos negócios e em defesa da população, face às conseqüências mais sinistras da "anarquia de mercado" (BAUMAN, 1999, p.74).

A análise do autor implica ainda em discutir como o poder econômico do Estado se enfraqueceu e de como as possibilidades de ações coletivas, visando à defesa de seguidas perdas decorrentes desse processo, também se reduziram. Esse processo, ambíguo e complementar que ele entende como sendo a globalização (integração e divisão, globalização e territorialização, síntese e dispersão), poderia ser definido, mais corretamente, a partir de um conceito que ele toma de Roland Robertson, a glocalização, e que ele define como sendo, essencialmente, "o processo de concentração de capitais, das finanças e de todos outros recursos de escolha e ação efetiva", mas, sobretudo, uma concentração da liberdade de se mover e de agir.

István Mészáros (2005) não se preocupa em definir o que seja a globalização, mas procura demonstrar, por meio de uma reflexão filosófica sobre a dinâmica e a natureza do capitalismo, como a globalização pode ser percebida. Mészáros chega a sugerir a existência de um "fetiche globalizante", colocando a reflexão no campo dos mecanismos ideológicos da alienação de indivíduos e trabalhadores, devido a uma forma de internalização de valores e aspirações sociais a serviço da lógica do capital. Como a lógica do capital opera no sentido da mercantilização das relações sociais e humanas, ocorre uma instrumentalização dos mecanismos de produção e reprodução do "metabolismo social" em função dos “objetivos reificados do capital” (MÉSZÁROS, 2005, p. 48).

Essa dinâmica do capital se dá num ritmo crescente, colocando em risco a própria sobrevivência das sociedades. Ao estimular a criação de necessidades artificiais de consumo para manter o ciclo de produção e reprodução da formação e acumulação do capital, coloca em risco, também, a capacidade ambiental e ecossistêmica de suportar essa intensificação dos ritmos da produção e do consumo. Contraditoriamente, tal lógica opera no sentido de reforçar o distanciamento das classes sociais dos benefícios desse processo de reprodução do ordenamento social e produtivo, gerando desemprego, empobrecimento, exclusão e violência social, na mesma proporção em que perpetua uma elitização dos empregos socialmente valorados e reconhecidos, os quais permitem acúmulo de riquezas e bens, e inclusão em práticas globais ideologicamente valorizadas, devido à função alienante exercida pela mídia. Tal situação, devido ao seu grau de perversidade, não deixa de causar inquietação e revolta; daí, a necessidade do isolamento protetor dos grupos sociais, agentes econômicos e indivíduos beneficiados por essa lógica do capital, função 
essa exercida e cobrada dos agentes policiais e instâncias repressoras locais, regionais, nacionais e internacionais.

Dessa forma, é possível entender que a globalização econômica para Mészáros (2005), é um estágio do desenvolvimento histórico do capitalismo em que se acentua uma "crise estrutural do sistema do capital global", no qual se intensificam a mercantilização das relações sociais e humanas, a produção destrutiva, as desigualdades sociais, e os "círculos viciosos de desperdício e escassez". Assim, a globalização capitalista é uma manifestação contraditória dessa crise, no contexto de um novo reordenamento social e produtivo que, no entanto, cria possibilidades reais e concretas de ruptura (MÉSZÁROS, 2005, p. 76). Tais possibilidades de ruptura com o ordenamento do sistema do capital, no entender do autor, estão intrinsecamente associadas ao papel desempenhado pela educação. Apesar da instrumentalização realizada pelo sistema do capital, há possibilidades radicalmente transformadoras, se acompanhadas de mudanças essenciais no seu dinamismo e articulada ao trabalho universalizado, enquanto prática socializadora de construção e acesso a um mundo melhor para se viver. Mészáros (2005) nos mostra que é possível construir um outro mundo, alternativo a este da globalização perversa.

\section{Educar para um outro mundo possível}

Com base nas abordagens de Mészáros, podemos considerar que, no atual sistema regido pela lógica do capital global, tanto na escola quanto nos mais diferentes espaços institucionais e na mídia há uma transmissão de idéias, conceitos e valores forjados em função de interesses mercadológicos. É um tipo de educação, que internaliza e naturaliza as desigualdades provocadas pela crueldade do sistema capitalista. Para romper com essa lógica, a escola, como instituição de educação formal, teria um papel a cumprir, contribuindo para a formação de pessoas que pudessem assumir um posicionamento crítico acerca da organização social vigente.

Outros espaços, além da escola, seriam imprescindíveis para efetivar essa formação. As aprendizagens podem ocorrer em muitos lugares - associações, encontros, congressos, fóruns etc. - e as interações entre as pessoas, nesses espaços, poderiam favorecer a constituição de um mundo de aprendizagens em rede, onde as pessoas discutissem os problemas inerentes à realidade atual e as possíveis estratégias de enfrentamento. 
A Educação, de uma forma mais ampla, teria como objetivo o enfrentamento das internalizações hegemônicas a serviço do capital, com vistas a uma nova conscientização que supere a reificação do capital. A educação, nesse sentido, pode favorecer a construção de uma outra lógica, através da formação da consciência crítica, contra a educação consumista, contra a degradação ambiental, as desigualdades, as guerras, valorizando e assumindo os direitos humanos, a diversidade cultural, a participação de todos na vida social e nos processos decisórios. Ao mesmo tempo em que as pessoas se educam, interagindo coletivamente, podem organizar-se em movimentos, associações, cooperativas, para colocar em prática uma outra forma de organização social, para um outro mundo possível.

Para Ângela Antunes (2002), a necessária mudança passaria pela construção do sonho da planetaridade, ou seja, o termo globalização seria substituído por planetarização, entendida como um processo de construção da comunidade humana, da cidadania planetária. Implica a superação de relações internacionais de dominação e o compromisso de todos com o planeta.

No entendimento de António Teodoro (2003), os educadores e intelectuais brasileiros têm desenvolvido uma forte atividade crítica das políticas públicas nos últimos anos, e podem contribuir para uma agenda política capaz de tornar historicamente possível a transformação da escola num espaço público e democrático, conscientizador de uma cidadania multicultural e de participação. Um espaço em que a consigna freireana da unidade na diversidade ganhe espaço de afirmação e se torne realidade na práxis cotidiana. Ainda segundo o autor, possivelmente, na primeira década do século XXI, a "resposta deverá ser encontrada numa diversificação e numa gestão local do currículo", que permita a passagem de um ensino uniforme, transmissivo e expositivo para um ensino centrado na gestão de situações diferenciadas e interativas de aprendizagem, para quais as novas tecnologias de informação e comunicação não só facilitam como exigem, o que acarretará alterações nas formas de trabalho dos professores (TEODORO, 2003, p.148).

A construção de um outro mundo possível é complexa e exige que se forme uma rede cada vez mais ampla de pessoas preocupadas com essa tarefa, relacionada com a nossa sobrevivência e com a sobrevivência do planeta.

Esse deve ser um desafio para todos que não aceitam a lógica capitalista como a única possível; todos que não aceitam saber que a maior parte da população está excluída das conquistas da humanidade e que já perceberam que o capitalismo não pode resolver o problema da pobreza como expressou de forma convincente Jeremy Seabrook: 
A pobreza não pode ser curada, pois não é um sintoma de doença do capitalismo. Bem ao contrário: é evidência de sua saúde e robustez, do seu ímpeto para uma acumulação e esforço sempre maiores... Mesmo os mais ricos do mundo se queixam sobretudo de todas as coisas que se devem privar... mesmo os mais privilegiados são compelidos a carregar dentro de si a urgência de lutar para adquirir. (apud BAUMAN, 1999, p. 87)

Educar para um outro mundo possível interessa a todos que estão preocupados com a própria continuidade da vida no planeta.

\section{Referências bibliográficas}

ANTUNES, Ângela (2002). Leitura do mundo no contexto da planetarização: por uma pedagogia da sustentabilidade. Tese (Doutorado) - Faculdade de Educação da Universidade de São Paulo. 286 f.

BAUMAN, Zygmunt (1999). Globalização: as conseqüências humanas. Rio de Janeiro: Jorge Zahar.

MÉSZÁROS, István. (2005). A educação para além do capital. São Paulo: Boitempo.

TEODORO, António (2003). Globalização e educação: políticas educacionais e novos modos de governança. São Paulo: Cortez e Instituto Paulo Freire.

\section{Autores}

\section{Elifas Levi da Silva}

Mestre em Ensino de Ciências, Modalidade Física - Instituto de Física da USP e Doutorando em Educação, na área de Ensino de Ciências e Matemática - Faculdade de Educação da USP

Telefones: 4437-4198 - 9653-0658 - 3091-7179

Endereço Residencial: Rua Visconde de Mauá, 94 - Vila Assunção - Santo André - SP

elifas_levi@uol.com.br

\section{Elisabete Ferreira Esteves Campos}

Mestre em Educação e Doutoranda na linha de pesquisa em Didática, Teorias de Ensino e Práticas Escolares - Faculdade de Educação da USP

Orientadora Pedagógica da Equipe de Orientação Técnica da Secretaria Municipal de Educação de São Bernardo do Campo

Telefones: 4229-6669 - 7269-8251

Endereço Profissional: Av. Wallace Simonsen, 222 - São Bernardo do Campo - SP

Telefone: 4336-7776

Endereço Residencial: Al. Cassaquera, 322, apto. 22 - São Caetano do Sul - SP

betecampos@terra.com.br 


\section{Lucimara Rocha de Oliveira}

Especialista em Psicopedagogia e Mestranda da FEUSP na área de Psicologia da Educação, Professora do curso de Letras nas disciplinas de Didática e Prática Pedagógica de Língua Portuguesa e Coordenadora de Estágio Supervisionado - Faculdade Metodista do Sul Paulista e Assistente Técnico-pedagógico do Ensino Fundamental do Centro de Formação Pedagógica de Itapeva

Telefones: (15) 3521-3909 (com.) - (15) 3521-4801 - (15) 9723-8795

Endereço Residencial: Rua Joaquim José de Almeida, 152 - Itapeva - SP

lurochaoliveira@ig.com.br

\section{Manuel Marquez Viscaíno Júnior}

Professor da Secretaria Municipal da Educação da Prefeitura Municipal de São Paulo

Telefone: 3681-2009

Endereço Comercial: Rua Amadeu da Ressurreição, 185 - Presidente Altino - Osasco 06216-180

Endereço Residencial: Rua General Lauro C. de Farias, 428 - Vila Mangalot - São Paulo viscainoperi@uol.com.br

\section{Como citar este artigo:}

SILVA, Elifas Levi da et al. Educar para outro mundo possível diante dos desafios colocados pela globalização capitalista. Revista Moçambras: acolhendo a alfabetização nos países de língua portuguesa, São Paulo, ano 1, n. 2, 2007. Disponível em: <http://www.mocambras.org >. Publicado em: março 2007. 